\title{
Cloning and Expression of Poly 3-Hydroxybutyrate Operon Into Escherichia coli
}

\author{
Maryam Jari ${ }^{1}$; Saeid Reza Khatami ${ }^{1, *}$; Hamid Galehdari ${ }^{1}$; Mohammad Shafiei ${ }^{1}$ \\ ${ }^{1}$ Genetics Department, Faculty of Science, Shahid Chamran University of Ahvaz, Ahvaz, IR Iran \\ *Corresponding author: Saeid Reza Khatami, Genetics Department, Faculty of Science, Shahid Chamran University of Ahvaz, Ahvaz, IR Iran. Tel: +98-6133338965, E-mail: srkhatami@ \\ scu.ac.ir
}

Received: November 22, 2013; Revised: March 10, 2014; Accepted: April 22, 2014

\begin{abstract}
Background: Poly 3-Hydroxybutyrate (PHB), a class of Poly Hydroxyalkanoates (PHAs), is a group of bacterial storage polymers, produced by various microorganisms in response to nutrient limitation. PHAs are biodegradable polymers which could be a good substitute for current petrochemical plastics. PHB has been synthesized during three enzymatic steps including three genes.

Objectives: Our aim was PHB production from recombinant bacteria.

Materials and Methods: Ralstonia eutropha was cultured and its genomic DNA was extracted. The phbCAB operon was amplified using designed primers. The fragment was cloned into pET-28a expression vector and then transformed into Escherichia coli BL21. Sudan black staining was used to show the production of PHB.

Results: The extracted recombinant plasmid was digested with restriction enzymes. Separation of the desired fragment from the vector was performed to prove the correct insertion of the PCR products into the vector. The colony PCR and sequencing results confirmed the successful transformation. The production of PHB was confirmed by Sudan Black B staining under a light microscope.

Conclusions: Various metabolic and fermentation methods have been used in some bacterial strains for PHB production. The use of a recombinant system harboring PHB synthesis genes can produce PHB in higher concentrations compare to natural PHA-producing bacteria. The present study was one of the most important and basic steps of designing a recombinant E. coli that can produce PHB.
\end{abstract}

Keywords: Cloning; Expression; phbCAB Operon; 3-Hydroxybutyrate; Recombinant; Bacteria

\section{Background}

Petrochemical plastics have been developed into a major industry and are resistant to natural and chemical breakdowns (1). Nondegradable plastic causes environmental problems. Alternatively, bioplastics are polyesters synthesized by bacteria under unbalanced growth conditions (2). Poly Hydroxyalkanoate (PHA), the most known source of bioplastics, is a potential candidate for substitution of petrochemical plastics, because of its biodegradability properties. Biodegradable polymers are made from renewable resources, and thus do not lead to depletion of finite resources (3). These biopolymers have many desirable physical and chemical properties of conventional synthetic polymers (4). To this point, high production costs have limited the use of biopolymers; however, if these costs be reduced, there would be a widespread economic interest (5).

PHAs are generally in the form of (R)- $\beta$-hydroxyl fatty acids (6). Poly 3-Hydroxybutyrate (PHB) is the most common PHA. The PHB biosynthetic pathway includes three enzymatic reactions, catalyzed by three distinct enzymes. In the first reaction, b-ketoacyl CoA thiolase (encoded by the phbA gene) condenses two acetyl-CoA molecules into acetoacetyl-CoA. The second reaction is the reduction of
acetoacetyl-CoA to (R)-3-hydroxybutyryl-CoA by an acetoacetyl-CoA dehydrogenase (encoded by the phbB gene). Finally, P (3HB) polymerase (encoded by the phbC gene) polymerizes the (R)-3-hydroxybutyryl-CoA monomers into PHB (7). Only a few bacteria such as Alcaligenes latus, Bacillus megaterium, Ralstonia eutropha, and Pseudomonas oleovorans have been used for the production of PHA. $R$. eutropha is a non-spore-forming, Gram-negative bacterium and the most common bacterium for PHA production (2). There are also some limitations associated with the use of natural PHA producers. Natural PHA-producing bacteria usually harbor native machinery for polymer degradation and are often hard to lyse, making the recovery of PHA difficult (2). Therefore, the use of recombinant bacteria is more useful in production of PHA. The use of recombinant Escherichia coli for PHA production is beneficial in some points as fast growth, high cell density, ability of using several cheap carbon sources, and easy purification (8).

\section{Objectives}

Our objective was cloning and expression of the phb

Copyright (C) 2015, Ahvaz Jundishapur University of Medical Sciences. This is an open-access article distributed under the terms of the Creative Commons Attribution-NonCommercial 4.0 International License (http://creativecommons.org/licenses/by-nc/4.0/) which permits copy and redistribute the material just in noncommercial usages, provided the original work is properly cited. 
operon of R. eutropha H16 to E. coli BL21, and then PHB production from the recombinant bacteria.

\section{Materials and Methods}

\subsection{Bacterial Strains, Plasmids and Culture}

Dried culture of R. eutropha H16 (DSM 428) was purchased (DSMZ, GmbH). R. eutropha was cultured on nutrient broth $(8 \% \mathrm{w} / \mathrm{v})$ at $30^{\circ} \mathrm{C}$ for 24 hours. Nutrient agar containing $5 \mathrm{~g}$ peptone, $3 \mathrm{~g}$ meat extract and $15 \mathrm{~g}$ agar was dissolved in $950 \mathrm{~mL}$ distilled water; the final $\mathrm{pH}$ was adjusted at 7.3. Distilled water was added up to $1 \mathrm{~L}$ and then the final solution was autoclaved. The E. coli BL21 (DE3) was obtained from Pasteur Institute of Iran. These strains were cultured on Luria-Bertani (LB) medium (9) at $37^{\circ} \mathrm{C}$ for 16 hours. The pET-28a expression vector was purchased from Pasteur Institute, Iran.

\subsection{Amplification}

The total genomic DNA of R. eutropha was extracted (9). The desired fragment (3851 bp for phbCAB genes) was amplified by designed primers which possessed cutting sites on their 5 ' ends for BamHI and HindIII restriction enzymes. The primers were designed by authors. The sequence of PHB BamHI-forward primer was GCCGGATCCATGGCGACCGGCAAA and the one for PHB HindIII-reverse primer was GCCAAGCTTTCAGCCCATATGCAGGCC. The Phusion ${ }^{\circledR}$ Master Mix kit with GC Buffer (Bio Lab, New England) was used for amplification of this fragment. The thermo-cycler program was as follows: $98^{\circ} \mathrm{C}$ for three minutes, then 30 cycles of $98^{\circ} \mathrm{C}$ for 15 second, $65^{\circ} \mathrm{C}$ for one minute, $72^{\circ} \mathrm{C}$ for two minutes, and Finally $72^{\circ} \mathrm{C}$ for 10 minutes.

\subsection{Production of Recombinant Vector}

The PCR product and pET-28a vector were digested by Bam HI and Hind III restriction enzymes at $37^{\circ} \mathrm{C}$ for 16 hours and they were purified from the gel. Purification was performed according to Silica Bead DNA gel extraction kit (Fermentas, CA). Afterwards, ligation of the PCR product and vector was performed by T4 ligase at $16^{\circ} \mathrm{C}$ for 16 hours.

\subsection{Bacterial Transformation and Restriction Di- gestion}

Competent cells were prepared using $\mathrm{CaCl}_{2}$ (9). The transformation was performed according to Green and Sambrook's guideline (9). To prove the successful cloning of PCR products, the plasmid DNA was extracted from some bacterial clones and digested with Bam $\mathrm{HI}$ and Hind III (Fermentas, CA) overnight at $37^{\circ} \mathrm{C}$ and the resulted fragments were loaded on $1 \%$ agarose gel.

\subsection{Expression Study}

The LB medium (supplemented with $30 \mu \mathrm{g} / \mathrm{mL}$ Kanamycin), inoculated with an overnight culture of recom- binant cells, was incubated at $37^{\circ} \mathrm{C}$ until reaching the optimized optical density. Afterwards, isopropyl l-betaD-thiogalactopyranoside (IPTG) was added at a final concentration of $0.4 \mathrm{mM}$ and the incubation continued for eight hours at $37^{\circ} \mathrm{C}$ with shaking at $150 \mathrm{rpm}$. The cells were harvested by centrifugation at $5000 \mathrm{rpm}$ for 10 minutes.

\subsection{Poly 3-Hydroxybutyrate Staining}

A thin bacterial smear was made on the clean glass slide. The smear was air-dried and stained with a 3\% Sudan Black B solution (3 gram w/100 mLv in 70\% ethanol, Sigma) for 10 minutes. The smear was washed and air-dried. The sample was stained with Safranin (5\% w/v in distilled water, Sig ma) for 10 seconds, washed again with distilled water, and dried and observed under oil immersion lens (10).

\section{Results}

In R. eutropha, the lengths of phbC, phbA and phbB genes were respectively $1770 \mathrm{bp}, 1182 \mathrm{bp}$ and $741 \mathrm{bp}$. A pair of primers was designed for amplifying the phbCAB genes, which include the beginning of the phbC gene to the end of the phbB gene and the HindIII and BamHI restriction site sequence was added to the ends of the primers. PCR was accomplished by these primers and the desired fragment was amplified. The PCR product was checked by $1 \%$ agarose gel and a $3851 \mathrm{bp}$ fragment was seen (Figure 1). The pET-28a recombinant vector was constructed as described above; it is about $9200 \mathrm{bp}$. After transformation of the pET-28a recombinant vector including the desired insert into E. coli, a number of the single colons were taken from the selective medium (LB-kanamycin). Afterwards, the plasmid was extracted. The transformation was confirmed with colony PCR, digestion of extracted plasmid (Figure 2), and sequencing. After the digestion, the PCR product (3851 bp) and the PET-28a vector (5369 bp) were separated. Production of PHB was confirmed by Sudan Black B staining under a light microscope (Figure 3).

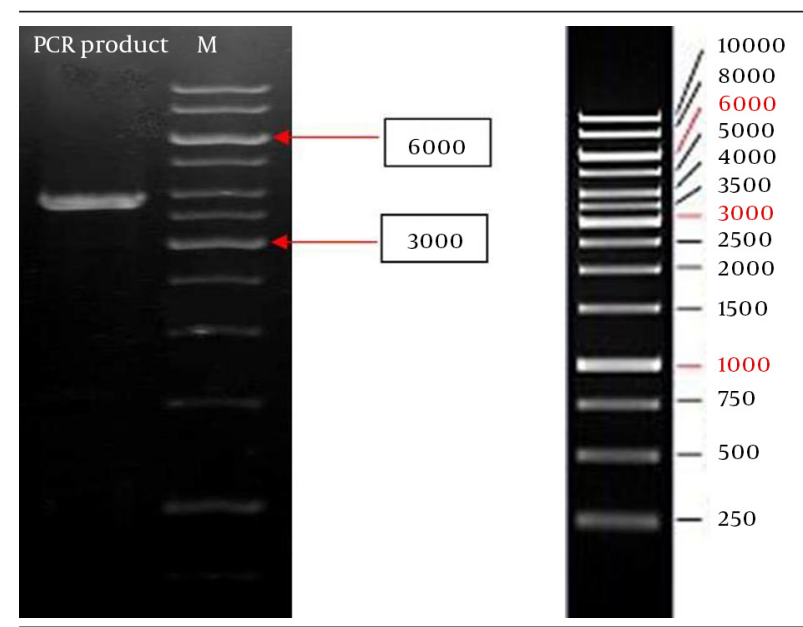

Figure 1. Polymerase Chain Reaction Result on 1\% Agarose Gel. The right lane is $1 \mathrm{~kb}$ DNA size marker (Fermentas, CA) and the left lane is the PCR product (3851 bp). 


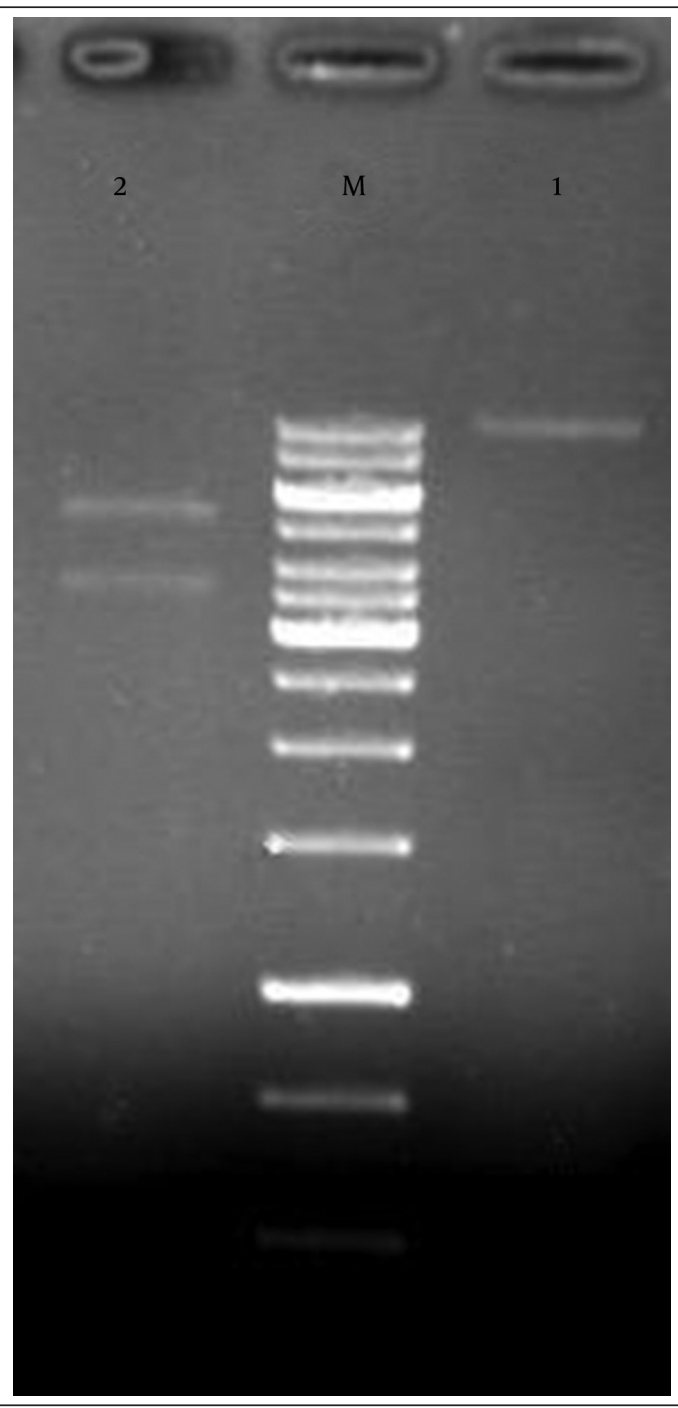

Figure 2. Digestion of the Extracted Plasmid .1) First digest of the recombinant plasmid; 2) double-digest of the recombinant plasmid; M) $1 \mathrm{~kb}$ DNA size marker.

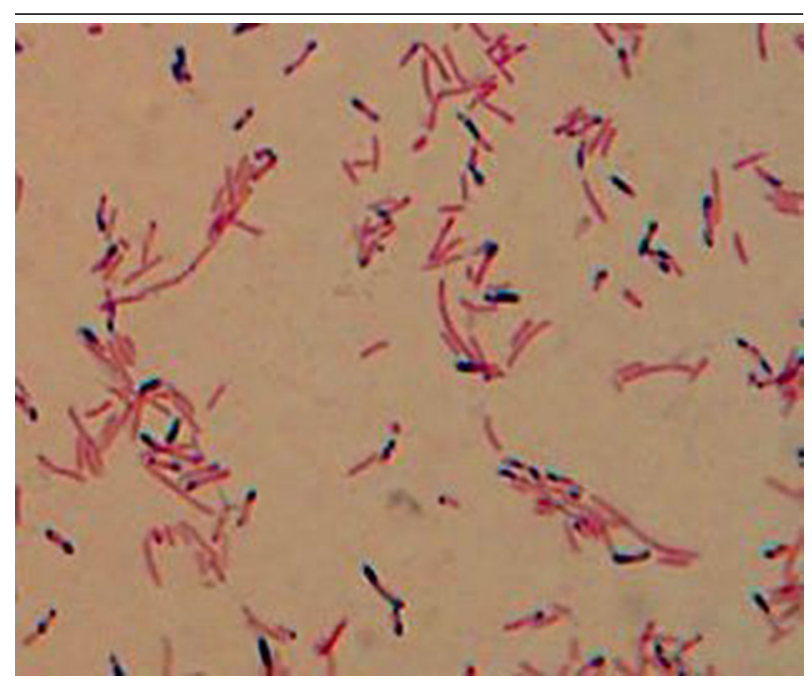

Figure 3. Sudan Black Staining of Poly 3-Hydroxybutyrate Granules

\section{Discussion}

PHAs are biodegradable polymers which could be a good substitute for current petrochemical plastics. PHAproducing genes exist in various bacteria. Although these genes are dispersed on chromosome in some organisms, they are in tandem in other bacteria such as R. eutropha H16. Although the capacity of $R$. eutropha to produce and accumulate polymers is well-known, the use of these kinds of bacteria has some limitations. Hence, many efforts have been accomplished to create recombinant bacteria and use economic carbon sources. In a report by Galehdari et al. (11) they separately amplified the phbB, phbA and phbC genes from the extracted Azotobacter genome and cloned the fragments in $\mathrm{pCR}^{\circledR} 2.1-\mathrm{TOPO}^{\circledR}$ cloning vector with subsequent transformation of $E$. coli $\mathrm{DH} 5 \alpha$. In their study, three types of recombinant E. coli were created and none of them could produce PHB. In our study, the whole operon of PHB was extracted and an expression vector was constructed; then, the production of PHB was confirmed in the recombinant bacteria. Many other reports used phb genes from $R$. eutropha and A. latus for production of PHB in E. coli $(12,13)$. Various metabolic and fermentation methods have been used in some bacterial strains for PHB production. The use of a recombinant system harboring the PHB synthesis genes can produce PHB in higher concentrations compare to natural PHA-producing bacteria (2). The high-yield production of PHB in natural PHA-producing bacteria can be reduced by high activity of intracellular depolymerase. To overcome this bottleneck, metabolically-engineered $E$. coli strains (without dehydrogenase) harboring heterologous PHA synthesis have been established (14).

Intensive efforts are being made to reduce the cost of production by means of bioprocess designing and metabolic engineering of the production strains (2). In this study, we successfully cloned and expressed the recombinant pET-28a containing the PHB-biosynthesis genes. PHB granules were observed in E. coli by Sudan Black B staining under the light microscope. In Sudan Black B staining, lipid inclusion granules were stained blue-black or blue-grey, whilst the bacterial cytoplasm was stained light pink. Therefore, PHB was produced from the recombinant E. coli BL21.

\section{Acknowledgements}

The authors appreciate from genetics laboratory and biotechnology center of Shahid Chamran University of Ahvaz, Ahvaz, IR Iran.

\section{Authors' Contributions}

This work is part of the Master thesis of Maryam Jari and she wrote the paper. Saeid Reza Khatami was the supervisor of the thesis and edited the manuscript. Hamid Galehdari was the co-supervisor of the thesis. Mohammad Shafiei was the adviser of the thesis. All the authors read and approved the final manuscript. 


\section{Funding/Support}

This study was financially supported by a grant (No. 636410) from Shahid Chamran University of Ahvaz, Iran.

\section{References}

1. Sudesh K, Iwata T. Sustainability of biobased and biodegradable plastics. Clean (Weinh). 2008;36(5 - 6):433-42.

2. Chee JY, Yoga SS, Lau NS, Ling SC, Abed RMM, Sudesh K. Bacterially produced polyhydroxyalkanoate (PHA): converting renewable resources into bioplastics. Cur Res Tech Educ Topics in Appl Microb Microb Biotech. 2010;2:1395-404.

3. Byrom D. Production of poly- $\beta$-hydroxybutyrate: poly- $\beta$ hydroxyvalerate copolymers. FEMS Microbiol Rev. 1992;9(24):247-50.

4. Amass W, Amass A, Tighe B. A review of biodegradable polymers: uses, current developments in the synthesis and characterization of biodegradable polyesters, blends of biodegradable polymers and recent advances in biodegradation studies. Polym Int. 1998(47):89-144.

5. Nishida H, Tokiwa Y. Effects of higher - order structure of poly (3 - hydroxybutyrate) on its biodegradation. I. Effects of heat treatment on microbial degradation. J Appl Polym Sci. 1992; 46(8):1467-76.

6. Gorenflo V, Schmack G, Vogel R, Steinbuchel A. Development of a process for the biotechnological large-scale production of 4-hydroxyvalerate-containing polyesters and characterization of their physical and mechanical properties. Biomacromolecules. 2001;2(1):45-57.

7. Madison LL, Huisman GW. Metabolic engineering of poly(3hydroxyalkanoates): from DNA to plastic. Microbiol Mol Biol Rev. 1999;63(1):21-53.

8. Fidler S, Dennis D. Polyhydroxyalkanoate production in recombinant Escherichia coli. FEMS Microbiol Rev. 1992;9(2-4):231-5.

9. Green MR, Sambrook J. Molecular cloning: a laboratory manual. 4 ed; 2012.

10. Hartman TL. The use of Sudan Black B as a bacterial fat stain. Biotech \& Histochem. 1940;15(1):23-8.

11. Galehdari H, Alaee S, Mirzaee M. Cloning of poly (3-Hydroxybutyrate) synthesis genes from Azotobacter vinelandii into Escherichia coli. Jundishapur J Microbiol. 2009;2(1):31-5.

12. Chien CC, Hong CC, Soo PC, Wei YH, Chen SY, Cheng ML, et al. Functional expression of phaCAB genes from Cupriavidus taiwanensis strain 184 in Escherichia coli for polyhydroxybutyrate production. Appl Biochem Biotechnol. 2010;162(8):2355-64.

13. Choi JI, Lee SY, Han K. Cloning of the Alcaligenes latus polyhydroxyalkanoate biosynthesis genes and use of these genes for enhanced production of Poly(3-hydroxybutyrate) in Escherichia coli. Appl Environ Microbiol.1998;64(12):4897-903.

14. Tokiwa Y, Ugwu CU. Biotechnological production of (R)-3-hydroxybutyric acid monomer. J Biotechnol. 2007;132(3):264-72. 